\title{
Estimating milk loss based on somatic cell count at the cow and herd level
}

\author{
H. Chen, ${ }^{1} \odot$ A. Weersink, ${ }^{1 *} \odot$ D. Kelton, ${ }^{2} \odot$ and M. von Massow ${ }^{1} \odot$ \\ ${ }^{1}$ Department of Food, Agricultural and Resource Economics, University of Guelph, Guelph, Canada, ON N1G 2W1 \\ ${ }^{2}$ Department of Population Medicine, University of Guelph, Guelph, Canada, ON N1G 2W1
}

\begin{abstract}
There is a direct relationship between elevated somatic cell count (SCC) in an individual cow milk production and milk loss. This relationship has been used at the herd level to estimate an overall herd milk loss due to subclinical mastitis and to use recovery of this lost milk as a financial benefit to cover the cost of intervention strategies to improve milk quality. The objective of this study was to estimate the recoverable milk revenue on a per cow basis for herds moving from one herd average SCC level to a newer, lower level. Test-day records from 1,005,697 dairy cows in 3,741 herds between 2009 to 2019 were used. Milk yield loss for each cow in each herd on test day was estimated using a mixed effects regression equation, and then summed to estimated total herd milk loss. These herd average daily milk loss estimates were then related to the bulk tank SCC, and the distribution of underlying individual cow SCC were examined. The distributions in daily herd milk loss for various bulk tank SCC values were generated, and estimates of recoverable milk loss were generated to simulate a herd moving from their current bulk tank SCC to a new lower level. The results indicate that estimates of total herd milk yield loss vary with the distribution of cow-level SCC and parity within the herd, so it is imperative that milk loss be calculated on a per cow basis. Further, the recoverable milk loss estimates based on moving to a lower bulk tank SCC where milk loss is still occurring was relatively small compared with the traditional assumption that all milk loss would be recovered, and less than most herd owners and advisors would expect.
\end{abstract}

Key words: somatic cell count, dairy herd, milk loss

Received March 12, 2020.

Accepted February 20, 2021.

*Corresponding author: aweersin@uoguelph.ca

\section{INTRODUCTION}

Mastitis is one of the costliest diseases affecting dairy cattle (DeGraves and Fetrow, 1993; Seegers et al., 2003). Costs associated with mastitis are attributable to both the clinical and subclinical forms of the disease, and are a consequence of reduced milk production, treatment, milk discard, and premature culling (Aghamohammadi et al., 2018). The unrealized income from milk production losses attributable to subclinical mastitis are accepted to be higher than the costs of clinical mastitis (Aghamohammadi et al., 2018).

Elevated SCC in an individual cow's milk is the most commonly used indirect measure of subclinical mastitis, and it has been demonstrated that there is a direct relationship between elevation in SCC and milk loss (Raubertas and Shook, 1982; Hand et al., 2012). Estimated milk loss at the cow level was first reported by Raubertas and Shook (1982) as a function of a cow's parity and composite milk SCC, and their work was translated into commonly used tables for field-based estimates of milk loss, such as Hand et al. (2012). Over time, the methods used to estimate milk loss have evolved, and more recently it has been determined that not only the parity and absolute SCC value, but also the time a cow stays over a specified SCC threshold also affects the degree of milk loss (Halasa et al., 2009; Hand et al., 2012; Hadrich et al., 2018).

While methods have evolved to better describe the relationship between milk loss and SCC for an individual cow, less is known about the relationship between milk loss and SCC at the herd level. The bulk tank SCC could be plugged into the individual cow milk loss equation as developed by Raubertas and Shook (1982) to proxy an average milk loss for the herd. An alternative provided in this paper estimates milk loss for each individual cow in a herd and then sums up these estimates to determine not only an average milk loss for the herd but also its distribution. Herds with the same bulk tank SCC may have significant differences in average milk loss and those differences could have implications for the management decisions made to deal with subclinical mastitis. 
Investing in changes in management to reduce subclinical mastitis and improve udder health and milk quality compares the cost of the interventions to the benefit from recovered milk loss for the herd (McInerney et al., 1992). If one is to use the milk loss value as an indicator of how big the investment can be, one must assume that all of the milk loss is recoverable, which would mean that every cow could return to a SCC level of less than $100 \times 10^{3}$ cells $/ \mathrm{mL}$, the threshold at which milk loss starts to accrue (Raubertas and Shook, 1982; Hand et al., 2012). In most circumstances that is an unrealistic expectation, and thus the recoverable milk production and associated revenue is less than the estimate under the assumption that all milk loss can be eliminated. Further, given that the relationship between SCC and milk loss is not linear, and that the greatest milk loss occurs at relatively low SCC, the actual recoverable milk production can be substantially less than the estimate.

The objective of this study was to estimate the recoverable milk revenue on a per cow basis for herds moving from one herd average SCC to a newer, lower value. The benefit of improving milk yield through a reduction in SCC is calculated under 2 scenarios. First, the increase in milk yield is estimated for alternative reductions in the percentage of the herd with SCC greater than $200 \times 10^{3}$ cells $/ \mathrm{mL}$. The second is the increase in milk yield by reducing the bulk tank SCC depending on the percentage of the herd with SCC greater than $200 \times 10^{3}$ cells $/ \mathrm{mL}$. The calculations highlight the role of the distribution of individual cow SCC in the value of milk yield improvement. In addition, the methods give estimates on the amount of recoverable milk as a function of the current bulk tank SCC to a lower target level.

\section{MATERIALS AND METHODS}

\section{Data}

Test-day records from 1,005,697 dairy cows in 3,741 herds in Ontario, Canada, between 2009 to 2019 were obtained from CanWest DHI. The total number of testday records available was 18,229,504. Each test-day record contained a unique herd and animal identifier, breed, parity, DHI test date, DIM, 24-h milk yield ( $Y$ ), fat and protein yield, projected 305-d lactation milk, fat and protein yield, SCC, animal birth date, lactation starting date, lactation ending date, date the cow entered and left the herd, and the reason why the cow left. Records were eliminated if the value of a variable was in the 1st or 99th percentile, except for SCC. Any duplicate records were eliminated so that there is one test-day record per cow per month. This resulted in $15,585,859$ test-day records available for use in the following analysis.

\section{Methods}

The loss in milk yield per cow from subclinical mastitis as indicated by elevated SCC involves first estimating the factors affecting actual milk yield including SCC and then comparing it to potential milk yield. A mixed effects model is used to estimate milk yield determinants to account for the nonindependence of some observations. For example, observations on cows within the same herd will be correlated with one another since they are under the same management and live in the same facilities. Following the methods outlined in Hox et al. (2010), actual milk yield for each cow on each test day is estimated through the following mixed effects regression equation with herd level (categorical variable) nested in year level (categorical) as random effects to account for the clustered nature of the data using a restricted maximum likelihood approach.

$$
\begin{gathered}
Y=\beta_{0}+\beta_{1} \operatorname{lnSCC}+\beta_{2} \mathrm{DIM}+\beta_{3} \text { Season } \\
+\mathbf{Z} \boldsymbol{\mu}+e,
\end{gathered}
$$

where $Y$ is actual 24-h milk yield $(\mathrm{kg})$ for each cow on each test day, SCC is the somatic cell concentration $(x$ $10^{3}$ cells $/ \mathrm{mL}$ ), DIM is days in milk (limited between 15 and 400), Season is a dummy variable equal to 1 if test day $j$ was in the warm months of May to September and 0 otherwise, $\beta$ are the fixed effects coefficients for the explanatory variables, $\mathbf{Z}$ is the design matrix of the random effects, $\boldsymbol{\mu}$ is the random effect coefficient matrix for $\mathbf{Z}$ with residual error at the year and herd level (nested with year level), and $e$ is the random error term at individual observation level with a mean equal to 0 and a constant variance. All records were divided into 4 subgroups based on parity with records of parity 4 and higher combined. A milk yield regression (Equation [1]) was estimated for each of the 4 parity groupings.

Estimated daily milk yield per cow $(\hat{Y})$ is calculated by plugging in the actual values for the explanatory variables into the regression estimates for [1]. Maximum potential daily yield per cow $\left(Y^{M a x}\right)$ also uses [1] but assumes no loss in production for a cow with a daily SCC less or equal to $100 \times 10^{3}$ cells $/ \mathrm{mL}$ (Hand et al., 2012). Note that the units for SCC of $\times 10^{3}$ cells/ $\mathrm{mL}$ will not be displayed for the rest of the paper. Milk yield loss in a 24 -h period (YL) due to elevated SCC is the difference between the estimates for maximum yield and actual yield. 


$$
\mathrm{YL}_{i, j, k, n}=\left\{\begin{array}{c}
0 \text { if } \mathrm{SCC}_{i, j, k, n} \leq 100, \text { otherwise } \\
Y_{i, j, k, n}^{\max }-\widehat{Y_{i, j, k, n}}=\widehat{\beta_{1}} \cdot \ln \left(\frac{100}{\mathrm{SCC}_{i, j, k, n}}\right),
\end{array}\right.
$$

where $\widehat{\beta_{1}}$ is the estimated coefficient on $\operatorname{lnSCC}$ in [1] and $\mathrm{SCC}_{i, j, k, n}$ is the SCC values for cow $i$ in parity subgrouping $j$ in herd $k$ at test day $n$.

Daily milk loss by parity subgrouping for a set of discrete SCC values are estimated using Equation [2] to allow for a comparison to previous studies. Equation [2] is also used to calculate the YL for each of the 15.6 million test-day records based on the SCC, DIM, and the parity for the observation. In addition to determining the average daily $\mathrm{YL}$, the distribution of the losses across all records can be determined and exact value of milk loss estimates can be calculated based on Equation $[2]$.

Herd-Level Milk Loss. The daily total milk loss in herd $k$ at test day $n\left(\mathrm{TYL}_{k, n}\right)$ due to elevated SCC values is the sum of all milk loss for each cow within the herd:

$$
\mathrm{TYL}_{k, n}=\sum_{i=1}^{m} \mathrm{YL}_{i, k, n}
$$

where $m$ is the number of cows tested in herd $k$ at test day $n$. The average herd milk loss (AHYL) for herd $k$ is simply the average of across all $m$ cows in the herd:

$$
\mathrm{AHYL}_{k, n}=\left(\mathrm{TYL}_{k, n}\right) / m_{k, n} \text {. }
$$

The weighted herd-level SCC or bulk tank SCC for herd $k$ in test day $n$ is the weighted average of the individual cow SCC values $\left(\mathrm{SCC}_{i, k, n}\right)$ with the weights determined by the proportion of total production represented by the individual cow $(i)$.

$$
\text { Bulk tank } \mathrm{SCC}_{k, n}=\frac{\sum_{i=1}^{m} \mathrm{SCC}_{i, k, n} \times Y_{i, k, n}}{\sum_{i=1}^{m} Y_{i, k, n}} .
$$

This is the same method used by milk recording organizations to estimate the bulk tank SCC on any given test day. Note the actual bulk tank SCC for a herd may differ from that calculated in [5] as the bulk tank could contain milk from different days or for part of the day or herd.

The average daily milk loss per cow of a given herd is related to the bulk tank SCC, where $\alpha_{1}$ is the change in average daily milk loss per cow of a given herd from a unit change in the bulk tank SCC, through the following regression:

$$
\operatorname{AHYL}_{k, n}(\mathrm{~kg} / \mathrm{d})=\alpha_{1} \text { bulk tank } \mathrm{SCC}_{k, n}+e_{k, n} . \quad[6]
$$

While the individual cow daily milk losses (YL) are 0 when SCC $<100$, the AYHL will not be 0 even if the bulk tank SCC $<100$ unless the individual SCC values for all cows in the herd are less than 100 .

Individual vs. Herd-Level Milk Loss. A range of SCC values are substituted into Equations [2] and [6] to determine the effect of SCC on daily milk loss per cow at the individual cow level and the average for the herd. Using [2] to estimate AHYL will result in no loss for the herd if the SCC is less than 100 by definition, whereas the likely distribution of milk loss across cows within the herd suggests that AHYL will not be zero. The extent of the difference between estimating herd milk loss using the individual cow milk loss but with the bulk tank SCC in [2] versus [6] where the values for each cow in the herd with its individual SCC are determined with [2], and the relationship with bulk tank SCC calculated with [6] is an empirical question.

The distribution of YL and subsequently AHYL will vary across herds with the same bulk tank SCC. The resulting stochastic relationship for [6] is illustrated by plotting the AHYL for herds with a bulk tank SCC of 100,200 , and 300 on a test day. The AHYL for a wide range of bulk tank SCC values is also compared with the percentage of individual cow with SCC values greater than 200 in the herd.

Benefits of Reducing Bulk Tank SCC. The annual value per cow of reducing SCC is as follows:

$$
\begin{gathered}
\text { price of milk }(\$ / \mathrm{kg}) \times \alpha_{1}(\mathrm{~kg} / \mathrm{d} \text { per bulk tank SCC }) \\
\times(\Delta \text { bulk tank } \mathrm{SCC}) \times 365,
\end{gathered}
$$

which increases with the price of milk, the change in AHYL with a unit change in bulk tank SCC ( $\alpha_{1}$ from $[6]$ ), and the extent of the desired reduction in bulk tank SCC from its current to a target value $(\Delta$ bulk tank SCC).

The value of improving milk yield through a reduction in SCC is calculated under 2 scenarios. First, the increase in milk yield is estimated for alternative reductions in the percentage of the herd with SCC values greater than 200 to alternative target percentages. The second is the increase in milk yield by reducing the bulk tank SCC depending on the percentage of the herd with SCC greater than 200. The calculations highlight the role of the distribution of individual cow SCC in 
the value of milk yield improvement. In addition, the methods provide an estimate on the amount of recoverable milk as a function of the current bulk tank SCC to a lower target value.

\section{RESULTS AND DISCUSSION}

\section{Descriptive Statistics}

Approximately 3,000 herds were tested annually over the 11-yr period and the average size of these herds was 94 cows. Average annual herd size increased steadily over time to a maximum of 106 cows from 85 cows in 2009. Over $94 \%$ of the cows tested were Holstein. Average 24-h milk yield over the entire period was 31.2 $\mathrm{kg} / \mathrm{cow}$ with a minimum of $9.8 \mathrm{~kg} / \mathrm{cow}$ and a maximum of $57 \mathrm{~kg} /$ cow. Most records were within the first parity (39\%) and second parity (27\%) and the DIM averaged $177 \mathrm{~d}$ with a range from 8 to $510 \mathrm{~d}$.

The frequency distribution of individual cow SCC is illustrated in Figure 1. The average individual cow SCC was 187 with a significantly skewed distribution. The median was 65 and the majority $(63 \%)$ of the more than 15.6 million records had a SCC below 100 .
The frequency distribution of bulk tank SCC values at the herd level across the $11 \mathrm{yr}$ is illustrated in Figure 2 . The average bulk tank SCC of 171 is less but in the range of the average SCC value for the individual cow records (187). However, as expected the average bulk tank SCC was close to its median (174), suggesting the distribution is more symmetric compared with the heavily skewed distribution for the individual cow SCC records. Almost two-thirds (63\%) of the individual cow SCC were less than 100 but only $5 \%$ of the test-day bulk tank SCC values were less than 100. Dairy farmers in Ontario face a financial penalty if their bulk tank SCC exceeds 400 for any prolonged period of time. Only $0.6 \%$ of the test-day bulk tank SCC were above this threshold, even though $8.6 \%$ of the individual cow test-day records had SCC above 400.

\section{Milk Yield Regression Estimates}

The estimated coefficients for the milk yield Equation [1] are reported in Table 1 for each parity subgrouping. All explanatory variables were statistically significant at the $99 \%$ confidence level in each of the 4 regression equations and all coefficients had the

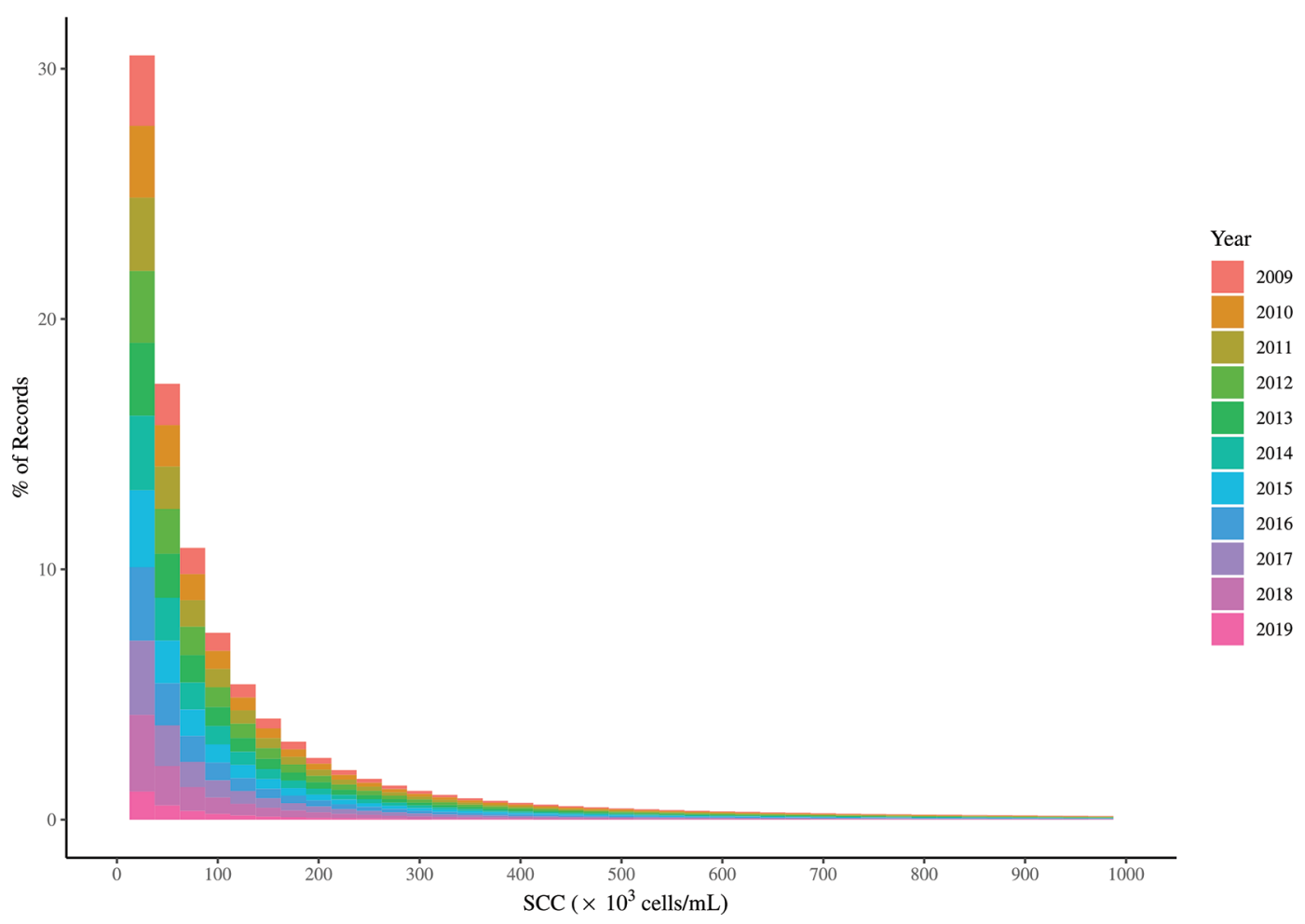

Figure 1. Individual cow test-day records of SCC. 


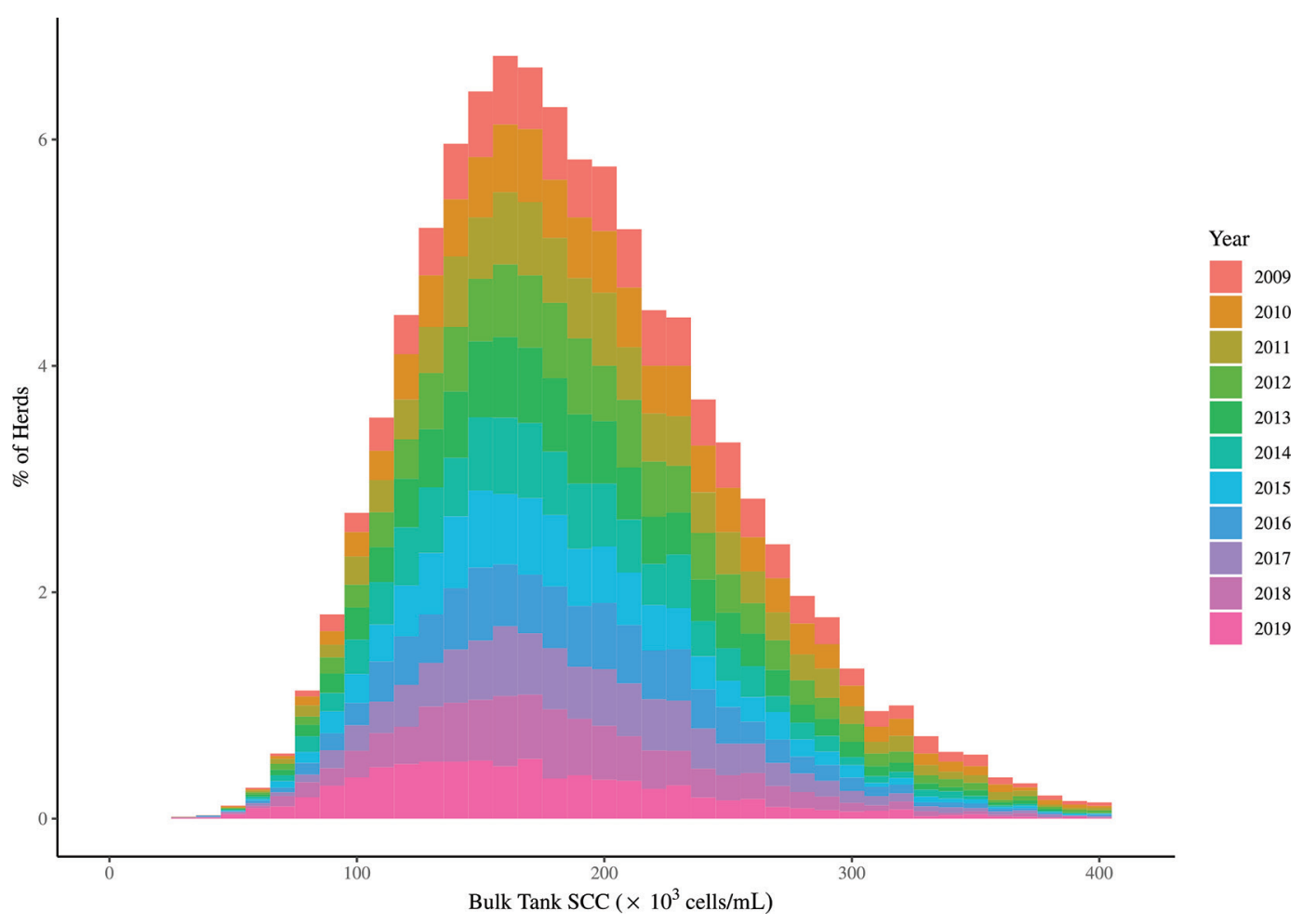

Figure 2. Herd bulk tank SCC test-day records.

expected sign. Increases in SCC decrease milk yield; the extent of this impact is discussed further below. As DIM increased, milk yield decreased, with the negative impact diminishing as lactation length increased. Milk yield was higher during the warmer months of the year by approximately by $0.4 \mathrm{~kg}$ per day for parity 1 cows and by $0.7 \mathrm{~kg}$ per day for longer parities.

\section{Individual Cow Milk Yield Loss Estimates}

The daily milk loss per cow (YL) for alternative SCC values by parity subgrouping estimated through Equation [2], where the estimate of $\beta_{1}$ is the coefficient on lnSCC in Table 1 , is listed in Table 2 . The values are comparable to those estimated by Hand et al. (2012),

Table 1. Mixed effects (year and herd as random effects) regressions fitted by REML ${ }^{1}$

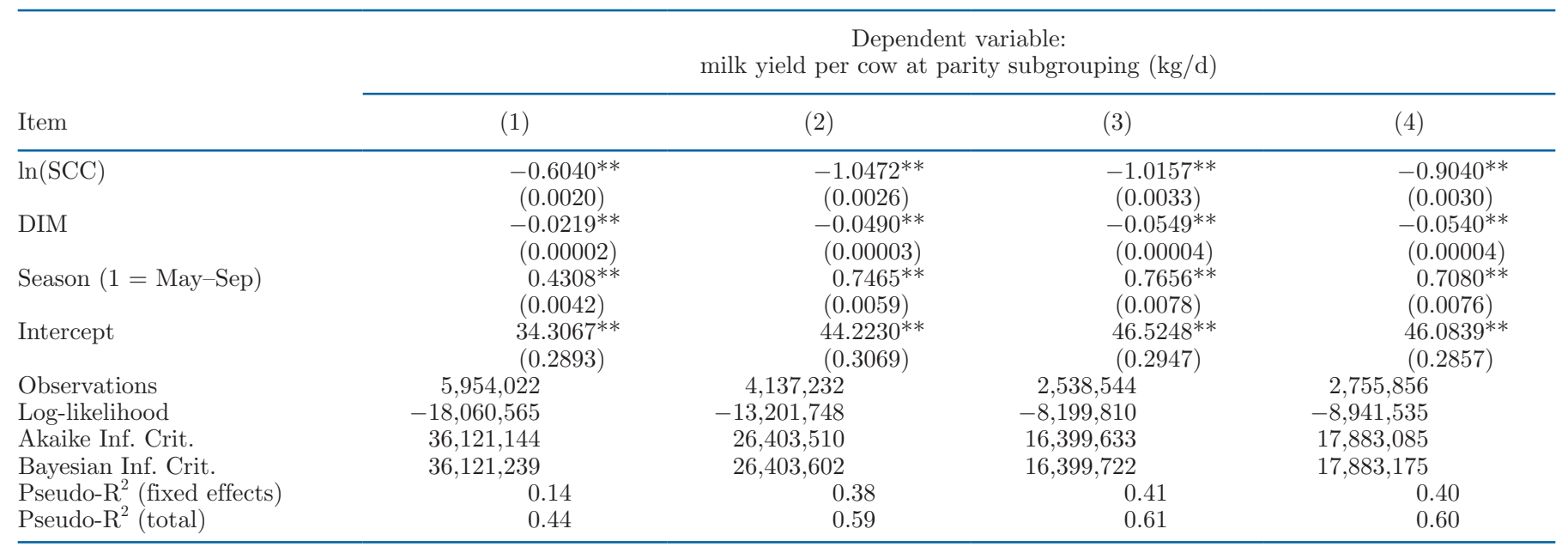

${ }^{1}$ Standard errors are shown below the estimates. Inf. Crit. = information criterion. $* * P<0.01$. 
Table 2. Estimated daily milk loss in kilograms (YL; and percentage of milk loss to milk yield) for specific values of cow-level SCC $\left(\times 10^{3}\right.$ cells $\left./ \mathrm{mL}\right)$ by parity ${ }^{1}$

\begin{tabular}{|c|c|c|c|c|c|c|c|c|}
\hline \multirow[b]{3}{*}{$\mathrm{SCC}$} & \multicolumn{8}{|c|}{ Parity subgrouping } \\
\hline & \multicolumn{2}{|c|}{1} & \multicolumn{2}{|c|}{2} & \multicolumn{2}{|c|}{3} & \multicolumn{2}{|c|}{4} \\
\hline & YL & $\%$ & YL & $\%$ & YL & $\%$ & YL & $\%$ \\
\hline 200 & 0.42 & 1.5 & 0.73 & 2.51 & 0.7 & 2.33 & 0.63 & 2.06 \\
\hline 500 & 0.97 & 3.36 & 1.69 & 5.43 & 1.63 & 5.03 & 1.45 & 4.45 \\
\hline 800 & 1.26 & 4.4 & 2.18 & 6.64 & 2.11 & 6.25 & 1.88 & 5.64 \\
\hline 1,000 & 1.39 & 4.78 & 2.41 & 7.38 & 2.34 & 6.88 & 2.08 & 6.11 \\
\hline 1,500 & 1.64 & 5.76 & 2.84 & 8.59 & 2.75 & 7.74 & 2.45 & 7.3 \\
\hline 2,000 & 1.81 & 6.01 & 3.14 & 9.24 & 3.04 & 8.82 & 2.71 & 7.75 \\
\hline
\end{tabular}

${ }^{1}$ Estimated using Equation [2].

who, in addition to parity, also estimated the effects by within herd milk production quartile. For example, the $1.69 \mathrm{~kg}$ milk loss (our estimation) in test day ( $24 \mathrm{~h}$ ) per cow for cows in parity 2 with an SCC of 500 is approximately the average of the values per milk production quartile $(1.42,1.77,1.92$, and 2.49) estimated by Hand et al. (2012). While comparable to the results of Hand et al. (2012), the negative effects of SCC on individual cow milk yield are higher than reported in other studies, perhaps due to either breed or management differences. Milk loss attributable to increased SCC are lowest in first parity cows and increase significantly with parity 2 cows, which is consistent with previously published estimates by Jones et al. (1984).
The daily milk loss per cow was also calculated across all 15.6 million test-day records using Equation [2] based on the SCC and parity subgrouping for an individual record. The estimated YL across all records are listed in Table 3 by SCC range and parity subgrouping. For example, $5.74 \%$ of the records were parity 1 cows with a SCC between 100 and 200 and the average YL for these records was $0.19 \mathrm{~kg}$. The average daily YL across all records was $0.34 \mathrm{~kg}$ per cow with a range from 0 to $3.37 \mathrm{~kg}$ per cow. Cows with SCC values less than 100 were constrained to have no milk loss due to the assumption of the difference between potential and actual milk yield. The assumed calculation of YL means milk loss increases with SCC values as expected,

Table 3. Estimated daily milk loss (YL) in kilograms for specific intervals of SCC $\left(\times 10^{3}\right.$ cells $\left./ \mathrm{mL}\right)$ by parity and percentage of all test-day records from 2009 to 2019

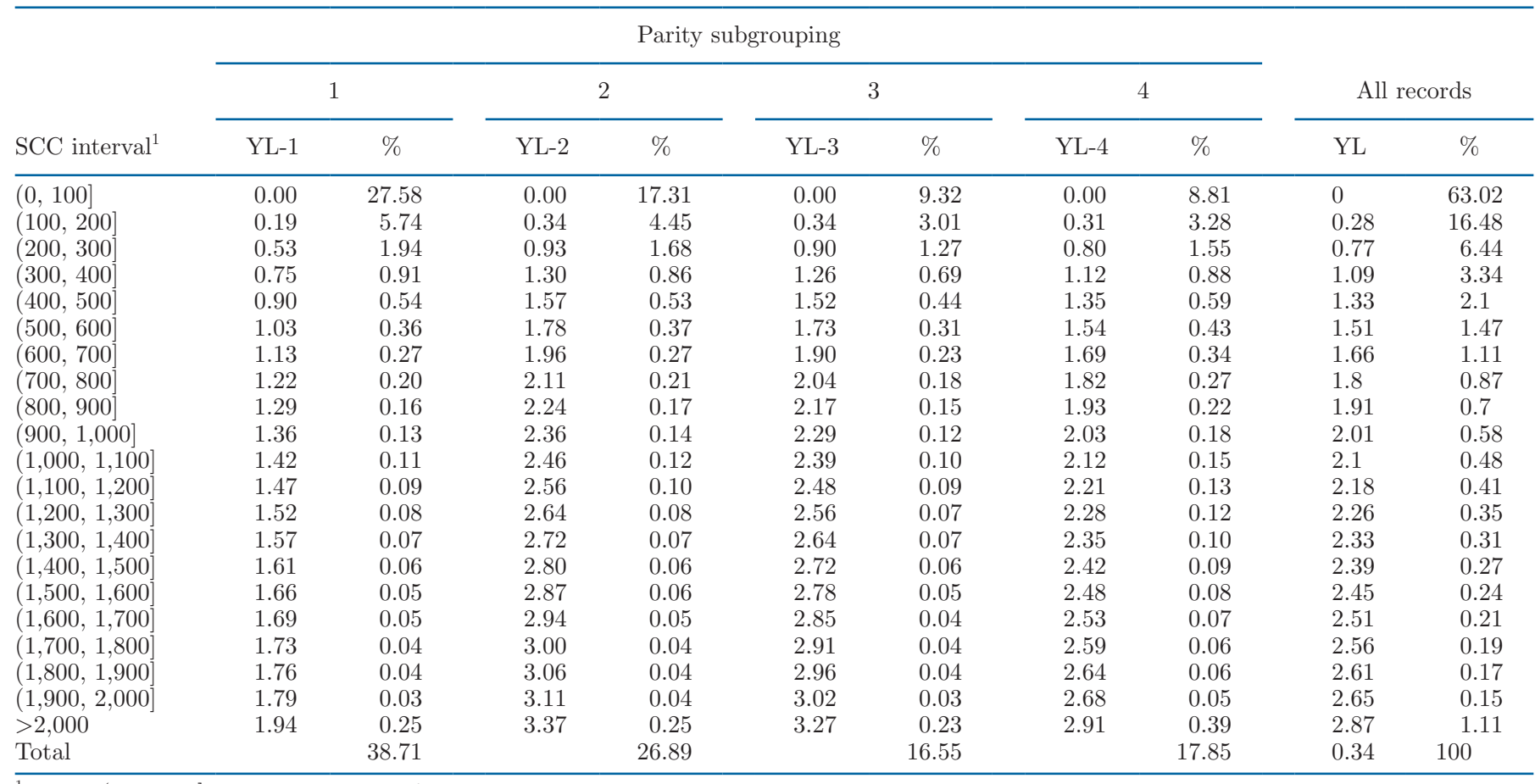

${ }^{1}$ Where $(100,200]$ indicates a range of $\geq 100$ and $<200$. 


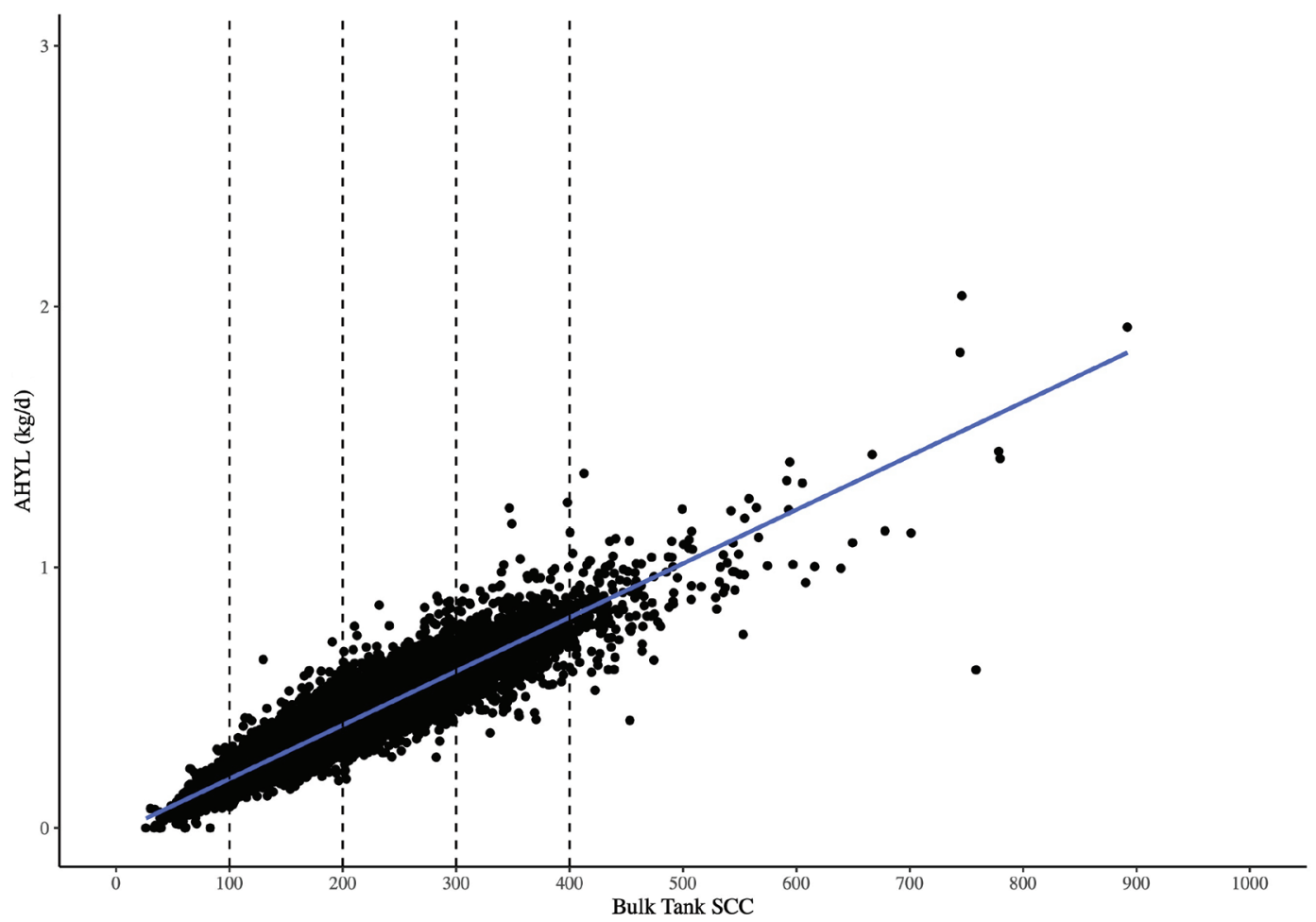

Figure 3. Average herd daily milk loss per cow (AHYL) versus bulk tank SCC $\left(\times 10^{3}\right.$ cells $\left./ \mathrm{mL}\right)$.

but the importance of Table 3 is the distribution of the loss across all records. Approximately $63 \%$ of the records tested over the 11-yr period had SCC values less than 100, whereas $16.5 \%$ of the cows tested had SCC between 100 and 200 and an average daily loss of $0.28 \mathrm{~kg}$ per cow. Over $90 \%$ of the test-day records had individual SCC less than 400.

\section{Herd Milk Yield Loss Estimates}

The distribution of daily milk loss across by SCC and parity subgrouping for individual cow records suggests that there will also be some degree of variation in herdlevel milk loss driven by the unique distribution of cow parity and SCC within the herd. The average milk loss per cow at the herd level (AHYL) by bulk tank SCC is illustrated for all test-day records in Figure 3. Overall as the bulk tank SCC increases, the herd-level milk loss increases, but there is a considerable range in milk loss per cow for a given bulk tank SCC.

The data presented in Figure 3 were used to estimate Equation [6] for which the results are as follows:

$$
\mathrm{AHYL}=0.0020 \times \text { bulk tank SCC. }
$$

The coefficient on bulk tank SCC is statistically significant $(t$-statistic $=15,830)$ and the adjusted $R^{2}$ value is
0.99. The strong fit for Equation $\left[6^{\prime}\right]$ is expected but the relationship is not deterministic as there is variation in average milk loss per cow per day for the herd around a given bulk tank SCC.

In calculating the milk loss at the herd level, one could use the bulk tank SCC and assume (incorrectly) that all cows have that individual SCC and use a milk loss per cow value for that SCC to estimate the milk loss for the herd. The predictions of daily milk loss per cow milk for various SCC values from the individual cow test-day record (Equation 2) and the average herd loss estimates (Equation $6^{\prime}$ ) are presented in Table 4. Aside from SCC less than 100 for which the YL is 0 by definition and there are positive albeit small AHYL values, the milk losses predicted by the individual cow approach are significantly higher than the average estimated for the herd. For example, at a SCC of 200, the YL is $37 \%$ higher than the AHYL $(0.60 \mathrm{~kg}$ per cow versus $0.38 \mathrm{~kg}$ per cow). The difference in the 2 approaches to estimating milk loss decreases as SCC increase, but do not come close to converging until SCC values are much higher than typically observed bulk tank SCC.

The distribution in daily herd milk loss across testday records for 3 specific bulk tank SCC values (100, 200, and 300) is illustrated in Figure 4. The observations drawn for each scenario in Figure 4 are represented along the vertical line for each of the $3 \mathrm{bulk}$ 

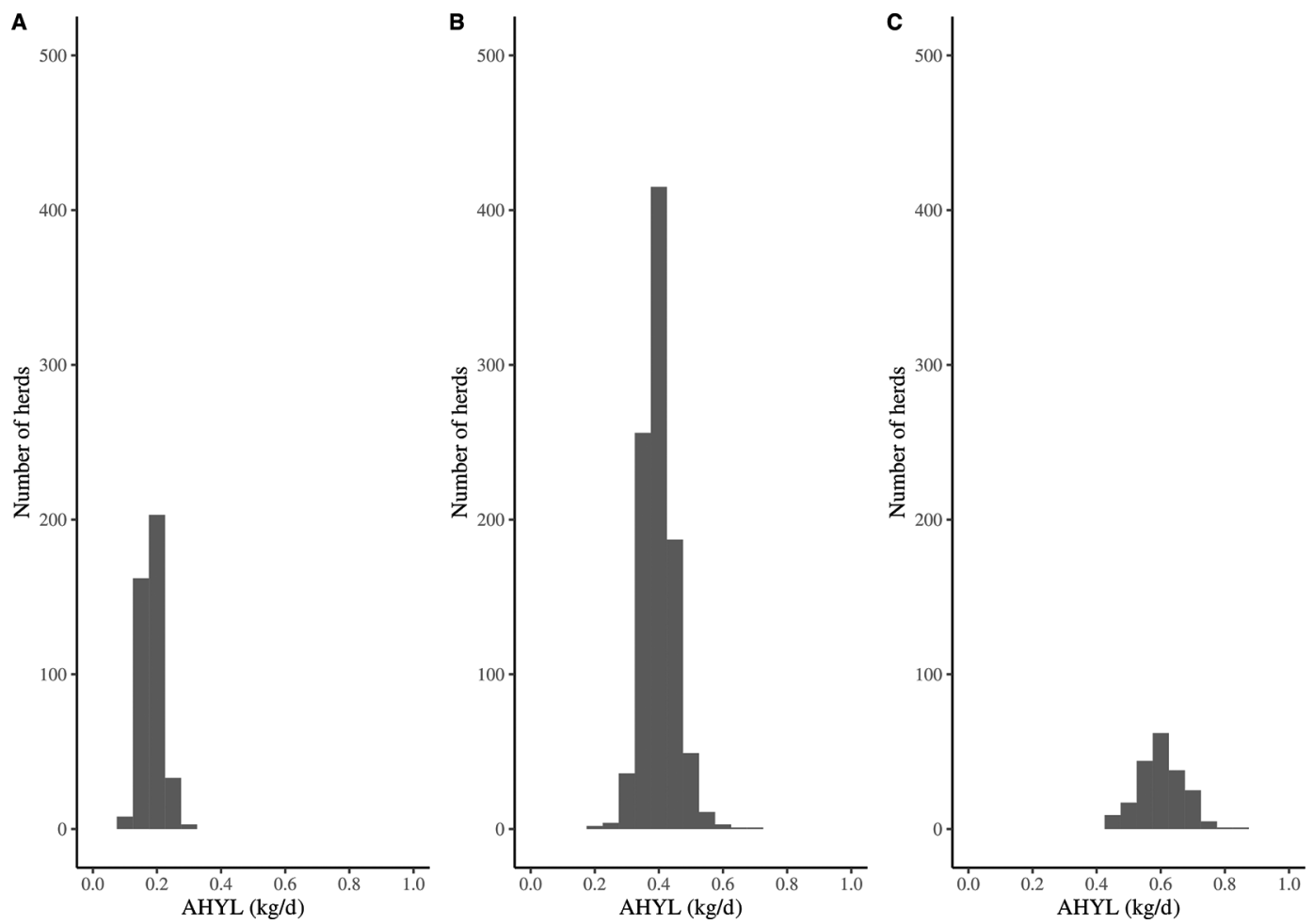

Figure 4. Average herd daily milk loss per cow (AHYL) for bulk tank SCC values $\left(\times 10^{3}\right.$ cells $\left./ \mathrm{mL}\right)$ of 100 (A), 200 (B), and 300 (C).

tank SCC values in Figure 3. Since the y-axis in Figure 4 represents the number of test-day records at the herd level rather than the relative frequency, the height of the bars for the 3 histograms reflects the number of herds. For example, 965 herds had a bulk tank SCC of 200 at a test day (panel B in Figure 4), 409 herds had a bulk tank SCC of 100 (panel A), and 202 herds had a bulk tank SCC of 300 (panel C). The mode of the distribution for AHYL is consistently lower but similar to the predicted individual cow daily milk loss for each of the SCC values. While there is no range by definition for the individual YL for a given SCC, there is an approximate $0.4 \mathrm{~kg} / \mathrm{d}$ per cow range in AHYL for a given bulk tank SCC and the range tends to increase with the SCC values.

The distribution in herd milk loss (Figure 4) is decomposed further by examining the distribution in the individual cow daily milk loss (YL) for 2 herds with the same SCC (Figure 5). For each of the 3 bulk tank SCC values shown in Figure 4 [100 (panel A), 200 (panel B), and 300 (panel C)], the herds at the 25th and 75th percentile for average herd milk loss (AHYL) are selected and the distribution in individual cow daily milk loss illustrated for that herd. For each of the 3 bulk tank SCC values, the herd at the 25th percentile of AHYL values for herds with the same

Table 4. Estimated daily milk loss (YL; kg per cow) for individual cow (Equation [2]) and average daily milk loss per cow for herd (AHYL; Equation $\left.\left[6^{\prime}\right]\right)$ for specific values of SCC $\left(\times 10^{3}\right.$ cells $\left./ \mathrm{mL}\right)$

\begin{tabular}{lcccc}
\hline $\begin{array}{l}\text { Individual SCC or } \\
\text { bulk tank SCC }\end{array}$ & $\begin{array}{l}\text { Individual cow } \\
\text { estimates (YL) }\end{array}$ & $\begin{array}{c}\text { Average herd } \\
\text { estimate (AHYL) }\end{array}$ & Difference & \% Difference \\
\hline 100 & 0.00 & 0.23 & -0.23 & - \\
200 & 0.60 & 0.38 & 0.22 & 37.3 \\
300 & 0.97 & 0.57 & 0.40 & 41.3 \\
400 & 1.23 & 0.75 & 0.47 & 38.6 \\
500 & 1.42 & 0.92 & 0.50 & 33.2 \\
600 & 1.59 & 1.06 & 0.52 & 20.3 \\
700 & 1.73 & 1.38 & 0.35 & 30.3 \\
\hline
\end{tabular}



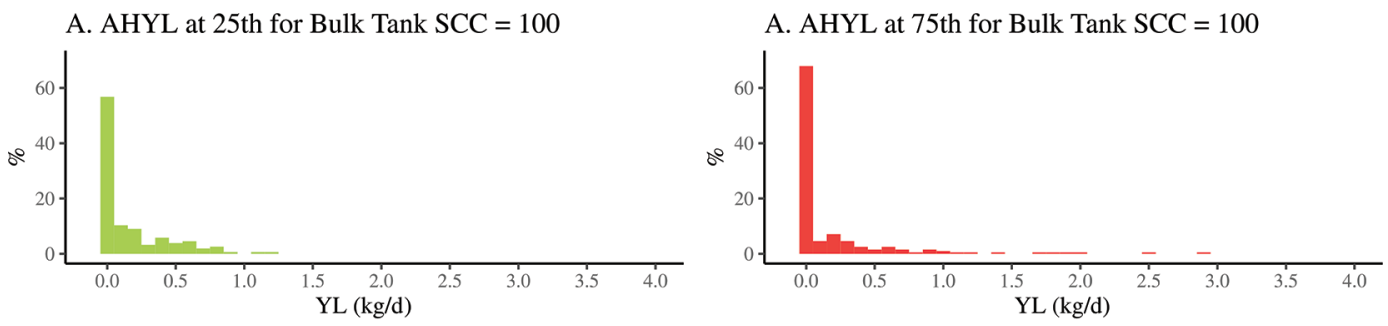

B. AHYL at 25th for Bulk Tank SCC $=200$

B. AHYL at 75 th for Bulk Tank SCC $=200$
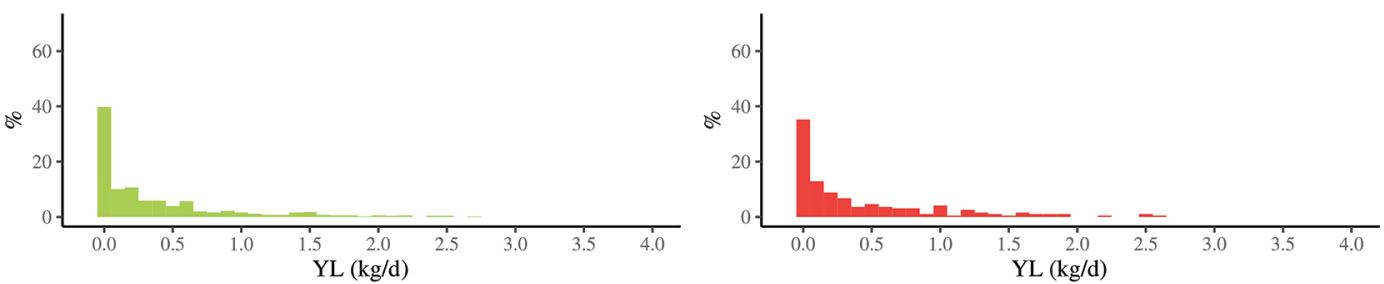

C. AHYL at 25th for Bulk Tank SCC $=300$

C. AHYL at 75th for Bulk Tank SCC $=300$
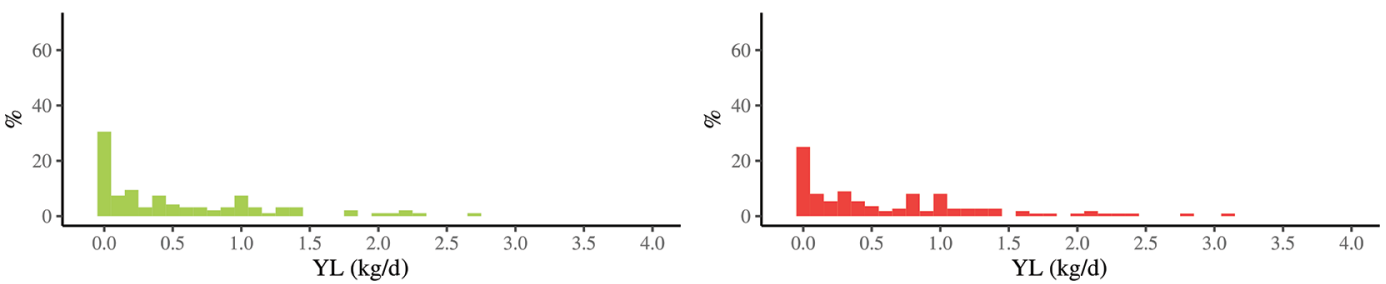

Figure 5. Histogram of individual cow daily milk loss (YL) for herds at 25th and 75th percentiles of average herd daily milk loss per cow (AHYL) with a bulk tank SCC $\left(\times 10^{3}\right.$ cells/mL) of $100(\mathrm{~A}), 200(\mathrm{~B})$, and $300(\mathrm{C})$.

bulk tank SCC have more of their herd with low SCC but more cows with extreme SCC than the herd at the 75th percentile of AHYL and same bulk tank SCC (McInerney et al., 1992). For example, the AHYL was $0.56 \mathrm{~kg} / \mathrm{d}$ per cow for the herd at the 25 th percentile for average herd milk loss among the 185 herds with a bulk tank SCC of 300. Whereas approximately $40 \%$ of this 25th percentile herd had an individual cow daily milk loss of 0 , several cows in the herd had a daily YL greater than $2 \mathrm{~kg} / \mathrm{d}$ (see panel C, 25th percentile, of Figure 5). In contrast, the AHYL was $0.64 \mathrm{~kg} / \mathrm{d}$ per cow for the herd at the 75 th percentile among herds with the same bulk tank SCC of 300. The distribution of individual milk loss for the cows in the herd on that test day was tighter and had a more uniform distribution compared with the herd at the 25th percentile. The percentage of the herd with no milk loss in the herd at the 75th percentile for AHYL is less than the herd at the 25th percentile but it had more cows with YL greater than $2 \mathrm{~kg} / \mathrm{d}$ per cow.

The distribution of individual cow SCC within a herd and its effect on the average herd-level milk loss is further described in Table 5, which lists the AHYL for various bulk tank SCC values, along with the percentage of individual cows in the herd with SCC over 200. For the 326 herds with bulk tank SCC less than 75 on a given test day, none had more than $20 \%$ of their herd with SCC greater than 200 and only 3 had 10\% to $20 \%$ of their herd with SCC greater than 200. As bulk tank SCC increased, the percentage of cows in the herd with SCC greater than 200 increases.

Most of the test-day records had herd bulk tank SCC greater than 150 and less than or equal to 175 . The AHYL (per cow) for these 5,385 herds was $0.32 \mathrm{~kg} / \mathrm{d}$, but the milk loss for individual herds within this bulk tank SCC category (150 to 175 ) varies depending on the distribution of individual cow SCC values. For example, the AHYL (per cow) was $0.31 \mathrm{~kg} / \mathrm{d}$ for the 3,926 herds that had 10 to $20 \%$ of the herd with SCC over 200 , whereas for the 1,443 herds with 20 to $30 \%$ of their herd with individual cow SCC greater than 200, the AHYL (per cow) was $0.35 \mathrm{~kg} / \mathrm{d}$. The pattern existed for all bulk tank SCC categories; average herd milk loss tended to increase with the percentage of individual cows in the herd with SCC over 200.

\section{Benefits of Reducing Bulk Tank SCC}

The value of reducing the bulk tank SCC can be determined using Equation [7]. Assuming a milk price of $\$ 0.80 / \mathrm{kg}$ and the estimate for $\alpha_{1}$ of 0.0020 , the annual benefit per cow of reducing bulk tank SCC by 100 is 
Table 5. Average daily milk loss per cow $(\mathrm{kg} / \mathrm{cow})$ at herd level (AHYL) by bulk tank SCC and percentage of herd with SCC over $200\left(\times 10^{3}\right.$ cells $/ \mathrm{mL}$ )

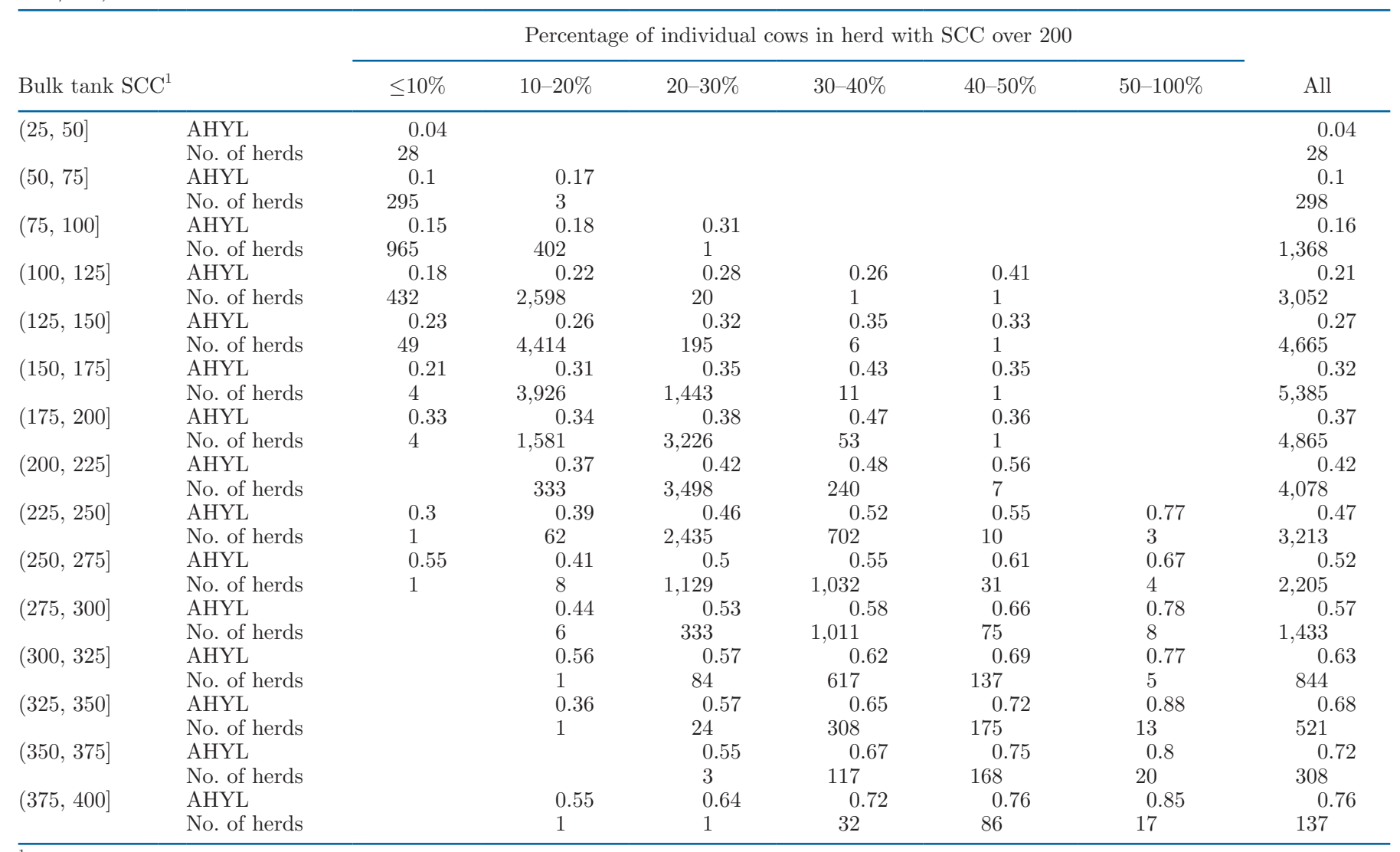

${ }^{1}$ Where $(25,50]$ indicates a range of $\geq 25$ and $<50$.

Table 6. Improvement in daily milk yield by reducing percentage of cows in herd with SCC greater than 200 $\left(\times 10^{3}\right.$ cells $\left./ \mathrm{mL}\right)$ for a given bulk tank SCC

\begin{tabular}{|c|c|c|c|c|c|}
\hline \multirow[b]{2}{*}{ Bulk tank $\mathrm{SCC}^{1}$} & \multirow{2}{*}{$\begin{array}{c}\text { Current \% of herd } \\
\text { with SCC > } 200\end{array}$} & \multicolumn{4}{|c|}{ Target $\%$ of herd with SCC $>200$} \\
\hline & & $\leq 10 \%$ & $10-20 \%$ & $20-30 \%$ & $30-40 \%$ \\
\hline$(125,150]$ & $\leq 10$ & $-^{2}$ & - & - & - \\
\hline$(125,150]$ & $10-20$ & 0.034 & - & - & - \\
\hline$(125,150$ & $20-30$ & 0.093 & 0.059 & - & - \\
\hline$(175,200]$ & $10-20$ & - & - & - & - \\
\hline$(175,200]$ & $20-30$ & - & 0.038 & - & - \\
\hline$(175,200]$ & $30-40$ & - & 0.131 & 0.093 & - \\
\hline$(225,250]$ & $10-20$ & - & - & - & - \\
\hline$(225,250)$ & $20-30$ & - & 0.073 & - & - \\
\hline$(225,250]$ & $30-40$ & - & 0.126 & 0.052 & - \\
\hline$(225,250]$ & $40-50$ & - & 0.173 & 0.1 & 0.048 \\
\hline$(275,300)$ & $10-20$ & - & - & - & - \\
\hline$(275,300]$ & $20-30$ & - & 0.087 & - & - \\
\hline$(275,300]$ & $30-40$ & - & 0.139 & 0.052 & - \\
\hline$(275,300]$ & $40-50$ & - & 0.215 & 0.128 & 0.076 \\
\hline$(275,300]$ & 50-100 & - & 0.219 & 0.167 & 0.091 \\
\hline$(325,350]$ & $10-20$ & - & - & - & - \\
\hline$(325,350]$ & $20-30$ & - & - & - & - \\
\hline$(325,350)$ & $30-40$ & - & - & 0.078 & - \\
\hline$(325,350]$ & $40-50$ & - & - & 0.141 & 0.063 \\
\hline$(325,350)$ & $50-100$ & - & - & 0.19 & 0.127 \\
\hline
\end{tabular}

${ }^{1}$ Where $(125,150]$ indicates a range of $\geq 125$ and $<150$.

2 
Chen et al.: SOMATIC CELL COUNT: COW VERSUS HERD MILK LOSS

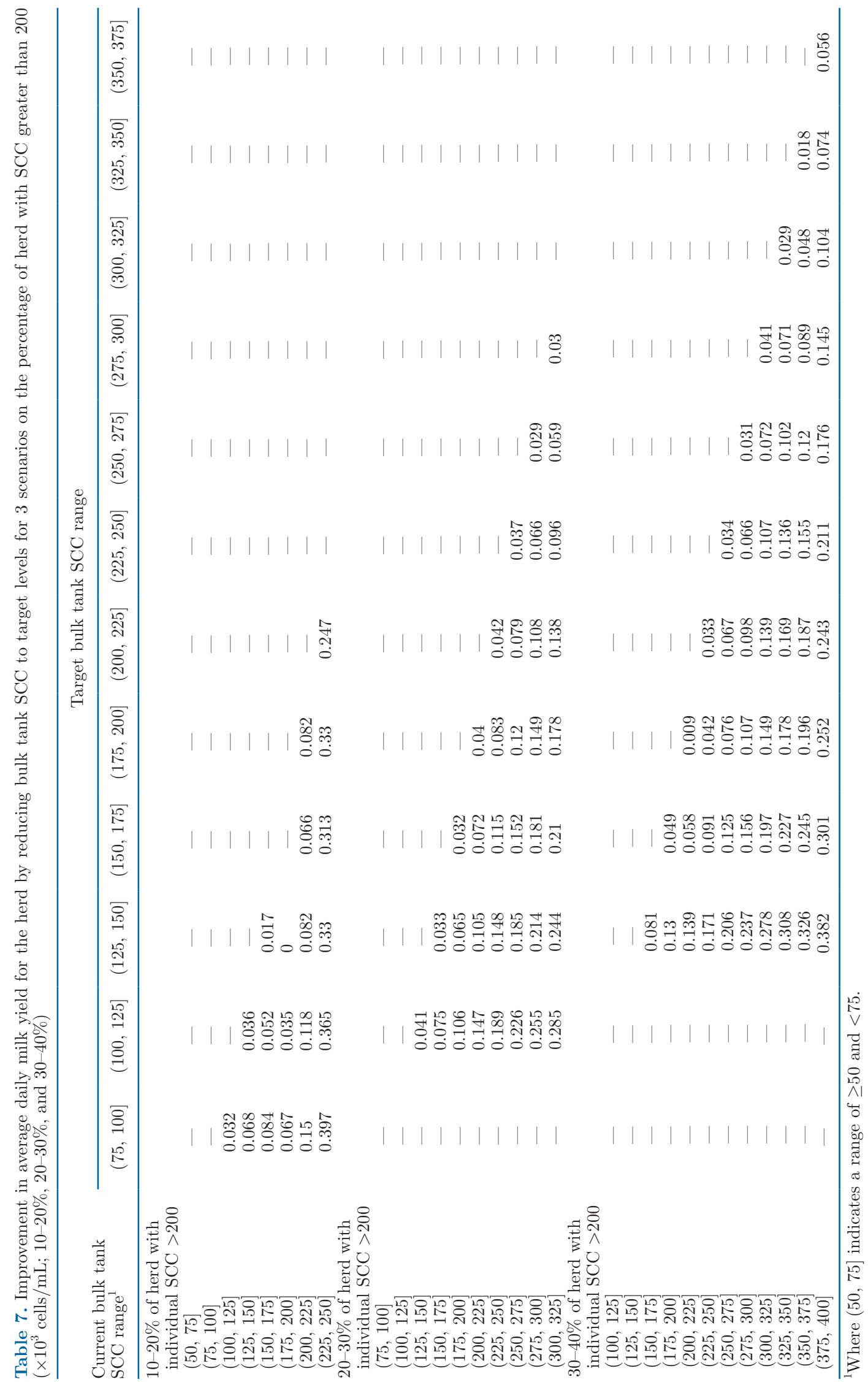


value of reduction in $\mathrm{SCC}=$ price of milk

$$
\begin{gathered}
\times \alpha_{1} \times(\Delta \text { bulk tank SCC }) \times 365 \quad\left[7^{\prime}\right] \\
=\$ 0.80 / \mathrm{kg} \times 0.0020(\mathrm{~kg} / \mathrm{d}) / \mathrm{SCC} \times 100 \mathrm{SCC} \times 365 \mathrm{~d} \\
=\$ 58.40 \text { per year per cow } .
\end{gathered}
$$

The annual benefit of reducing the bulk tank SCC increases with the price of milk and the extent of the desired reduction in SCC. Note that the value is expressed in Canadian dollars (Can $\$ 1=$ US $\$ 0.75$ ).

The value of $\$ 58$ per cow associated with a specific reduction in SCC is less than the total annual costs of mastitis of $\$ 662$ per cow estimated by Aghamohammadi et al. (2018) for a sample of Canadian dairy herds. However, the later study includes the costs of clinical mastitis (34\%) and preventative measures (15\%), and the $\$ 318$ associated with subclinical mastitis includes both milk yield reduction and culling. The milk yield loss for a herd estimated by Aghamohammadi et al. (2018) used the herd's SCC and an estimate of the reduction in production for a given SCC from Fetrow et al. (1988), which is a modification of the original approach suggested by Raubertas and Shook (1982). The optimal strategy for dealing with any dairy disease including mastitis is the one that minimizes total disease cost consisting of direct production losses plus prevention and treatment costs (McInerney et al., 1992; Chi et al., 2002). The value estimated here for milk production losses can be compared with preventative mastitis control measures (van Soest et al., 2016) and other costs from Aghamohammadi et al. (2018).

The improvement in milk yield can be achieved through either a reduction in the percentage of the herd with elevated SCC or through a general reduction in the bulk tank SCC. The former is illustrated in Table 6 , which uses the estimates from Table 5 to determine the reduction in milk yield loss by reducing the share of the herd with SCC greater than 200 for a given bulk tank SCC. For example, daily milk yield per cow is estimated to increase by $0.09 \mathrm{~kg}$ if the percentage of the herd with SCC greater than 200 can be reduced from 20 to $30 \%$ $(\mathrm{AHYL}=0.53)$ to 10 to $20 \%(\mathrm{AHYL}=0.44)$ for herds with a bulk tank SCC greater than 275 and less than or equal to 300 . This $0.09 \mathrm{~kg}$ per cow reduction in daily milk yield loss is roughly what can be attained for every 10-percentage point reduction in the share of the cows in the herd with SCC greater than 200.

The alternative means to increase milk yield is through a focus on the whole herd. Table 7 lists the increase in daily milk yield per cow by reducing the bulk tank SCC for 3 scenarios regarding the percentage of the herd with SCC greater than 200. For example, for herds with 20 to $30 \%$ of the cows with SCC greater than 200, reducing the bulk tank SCC from between 225 and 250 to between 150 and 175 increases daily milk yield by $0.115 \mathrm{~kg}$ per cow. The value is found by taking the difference in daily milk loss for the corresponding bulk tank SCC of 225 to 250 and 150 to $175(0.115=0.46-0.35)$. The greater the reduction in bulk tank SCC, the greater the reduction in milk loss as expected. There is an approximate 0.03 to $0.04 \mathrm{~kg}$ per cow improvement for every 25-point fall in the bulk tank SCC.

\section{CONCLUSIONS}

The objective of this study was to estimate the recoverable milk revenue on a per cow basis for herds moving from one herd average SCC to a newer, lower value. Our work determined that estimates of total herd milk yield loss should not be made from bulk tank SCC because the total herd milk loss will depend on the distribution of cow-level SCC and parity within the herd. Therefore, it is imperative that milk loss be calculated on a per cow basis. Further, it is important to realize that not all milk loss is recoverable, and so not available to be spent on remediation. The work described here suggests that the recoverable milk loss is relatively small, and certainly less than most herd owners and advisors would expect.

\section{ACKNOWLEDGMENTS}

The authors are grateful for the financial support provided by the Ontario Ministry of Agriculture, Food and Rural Affairs (Canada) and for the technical support provided by Michelle Edwards and Karen Hand at the University of Guelph (Guelph, Canada). The authors have not stated any conflicts of interest.

\section{REFERENCES}

Aghamohammadi, M., D. Haine, D. F. Kelton, H. W. Barkema, H. Hogeveen, G. P. Keefe, and S. Dufour. 2018. Mastitis-associated costs on Canadian dairy farms. Front. Vet. Sci. 5:100. https://doi .org/10.3389/fvets.2018.00100.

Chi, J., A. Weersink, J. A. VanLeeuwen, and G. P. Keefe. 2002. The economics of controlling infectious diseases on dairy farms. Can. J. Agric. Econ. 50:237-256. https://doi.org/10.1111/j.1744-7976 2002.tb00335.x.

DeGraves, F. J., and J. Fetrow. 1993. Economics of mastitis and mastitis control. Vet. Clin. North Am. Food Anim. Pract. 9:421-434.

Fetrow, J., K. Anderson, S. Sexton, and K. Butcher. 1988. Herd composite somatic cell counts: Average linear score and weighted average somatic cell count score and milk production. J. Dairy Sci. 71:257-260. https://doi.org/10.3168/jds.S0022-0302(88)79550-8.

Hadrich, J. C., C. A. Wolf, J. Lombard, and T. M. Dolak. 2018. Estimating milk yield and value losses from increased somatic cell count on US dairy farms. J. Dairy Sci. 101:3588-3596. https://doi .org/10.3168/jds.2017-13840. 
Halasa, T., M. Nielen, A. P. W. De Roos, R. Van Hoorne, G. de Jong, T. J. G. M. Lam, T. van Werven, and H. Hogeveen. 2009. Production loss due to new subclinical mastitis in Dutch dairy cows estimated with a test-day model. J. Dairy Sci. 92:599-606. https:/ /doi.org/10.3168/jds.2008-1564.

Hand, K. J., A. Godkin, and D. F. Kelton. 2012. Milk production and somatic cell counts: A cow-level analysis. J. Dairy Sci. 95:1358 1362. https://doi.org/10.3168/jds.2011-4927.

Hox, J. J., M. Moerbeek, and R. Van de Schoot. 2010. Multilevel Analysis: Techniques and Applications. Routledge. https://doi.org/10 $.4324 / 9780203852279$.

Jones, G. M., R. E. Pearson, G. A. Clabaugh, and C. W. Heald. 1984. Relationship between somatic cell counts and milk production. J. Dairy Sci. 67:1823-1831. https://doi.org/10.3168/jds.S0022 -0302(84)81510-6.

McInerney, J. P., K. S. Howe, and J. A. Schepers. 1992. A framework for the economic analysis of disease in farm livestock. Prev. Vet. Med. 13:137-154. https://doi.org/10.1016/0167-5877(92)90098-Z.

Raubertas, R. F., and G. E. Shook. 1982. Relationship between lactation measures of somatic cell concentration and milk yield. J. Dairy
Sci. 65:419-425. https://doi.org/10.3168/jds.S0022-0302(82)82207 -8 .

Seegers, H., C. Fourichon, and F. Beaudeau. 2003. Production effects related to mastitis and mastitis economics in dairy cattle herds. Vet. Res. 34:475-491.

van Soest, F. J. S., I. Santman-Berends, T. Lam, and H. Hogeveen. 2016. Failure and preventive costs of mastitis on Dutch dairy farms. J. Dairy Sci. 99:8365-8374. https://doi.org/10.3168/jds .2015-10561.

\section{ORCIDS}

H. Chen (1) https://orcid.org/0000-0002-5468-4642

A. Weersink () https://orcid.org/0000-0001-5081-3593

D. Kelton () https://orcid.org/0000-0001-9606-7602

M. von Massow (ํ) https://orcid.org/0000-0003-3945-4950 